\title{
Material Consuption Reduction and the Influence on the Mechanical Properties of the 3D Printed Parts for ABS Silver
}

\author{
TIBOR BEDO ${ }^{1}$, MIHAI ALIN POP ${ }^{1}$, VIRGIL GEAMAN ${ }^{1}$, IRINEL RADOMIR ${ }^{1}$, \\ AUGUSTIN SEMENESCU ${ }^{2}$, BRANDUSA GHIBAN ${ }^{2}$, BOGDAN FLOREA ${ }^{2 *}$ \\ ${ }^{1}$ Transilvania University of Brasov, 29 Eroilor Blvd., 500036, Brasov, Romania \\ ${ }^{2}$ University Politehnica of Bucharest, Faculty of Material Science and Engineering, 313 Splaiul Independentei, 060021, \\ Bucharest, Romania
}

\begin{abstract}
The main objective was to reduce the consumption of material when obtaining $3 D$ printed parts (different empty shapes inside) and the secondary one was to maintain the mechanical properties closer to the full printed version. In order to achieve these objectives, two internal config urations were designed - a configuration with hexagonal gaps (material reduction was 30\%) and a configuration with sinuous gaps (material reduction was 15\%). The specimens thus obtained were tested for traction, threepoint bending and shock (resilience). Hexagonal hollow configuration has a resistance values close to those of solid specimens but with the advantage of consuming with $30 \%$ less material.
\end{abstract}

Keywords: additive manufacturing, 3D printing, mechanical properties, consumption reduction

\section{Introduction}

Rapid prototyping (PR) or 3D printing as it is also known, is a relatively new technological process with a significant development in the last period. What until recently was impossible to achieve, namely that any object thought and designed by man, no matter how complex, to be made with the help of machines at everyone's fingertips has become a reality.

Currently, there is a lot of research in the field of $3 \mathrm{D}$ printing related to printing parameters, the type of filaments, the degree of filling of the walls, etc., but also through the development of new filaments with properties superior to those already existing.

In this paper we aim to analyze the physical and mechanical properties of 3D printed parts from acrylonitrile butadiene styrene (ABS) with two types of gaps: hexagonal and corrugated trying to keep as much of the physical and mechanical properties but with a reduction in material consumption.

Additive technologies (FFF in particular) are based on the principle of layer-by-layer deposition, starting from the base to the top of a hot extruded filament (in a semi-solid state), following a model (CAD) $[1,2]$.

The variety of usable materials that can be found in the form of powder, liquid, sheets or filament give an equally wide range of properties. If at the beginning, namely in the '80s the range of materials was limited, now the new materials have made a significant progress, reaching composite materials (polymer matrix + fiberglass, carbon fiber, etc.) to ceramic pastes [2-4].

With the $3 \mathrm{D}$ printing process, it is possible to obtain many types of parts with a high complexity of the shape and with low environmental impact at low production costs compared to conventional methods $[5,6]$.

Materials used has one of the most extensive application palettes among the additive manufacturing processes, from typical consumer goods to special applications such as medicine - prosthesis devices for human or animals, aerospace parts, and so forth [6-9].

The materials used in the field of 3D printing are varied but current research focuses both on their recycling and on obtaining new composite materials due to their properties and thus on the diversification of fields of application. 
The most common filaments used today are several types of polymer blends (PLA/PHA [10-13], PC/ABS [14], PU/PLA [14], etc.) and composites (polymer-carbon nanotubes [11, 15], polymer-ceramic $[15,16,18]$, polymer-metal [16], polymer-wood [17], etc.) formulations.

In order to improve the behavior of the material during hot extrusion, the researchers studied the possibility of introducing additives into the filament, like coupling agents, plasticizers, stabilizers, etc., to control the mechanical response to several degradation factors of the final 3D-printed polymer [5, 18, $19,24]$.

Several studies and research have been reported in the literature related to the mechanical behavior of 3D-printed structures originating from several types of filaments [20, 23, 24], the influence of build defects on the properties of the material or optimization of the layer height, printing duration or material consumption [21-28].

The novelty of this work resides in developing and characterizing two internal build architectures for 3D-printed materials, namely a hexagonal model structure and a sinuous architecture with an amount of materials consumed 30 and $15 \%$ less.

\section{Materials and methods}

\subsection{Samples design}

In the first phase and using the Solid Works Software were designed all the specimen type.

The 3D specimens were designed for mechanical tests (tensile, three-point bending and resilience) according to SR EN ISO 527-3: 2000 / AC: 2003. We started from a "full" printed test specimen, and then two variants were proposed, namely: the hexagonal gap version and the sinuous gap version.

The images of the test samples are presented in Figures $1 \div 3$.

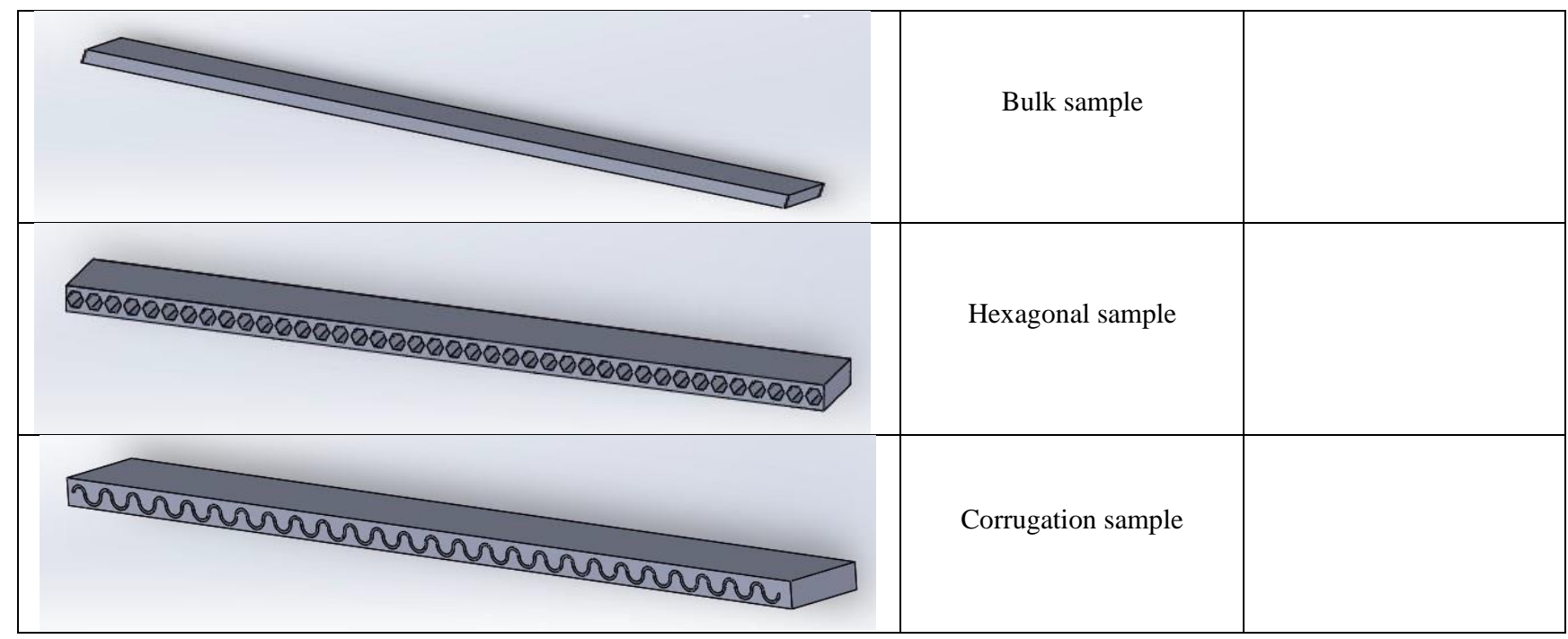

Figure 1. Three-point bending test samples

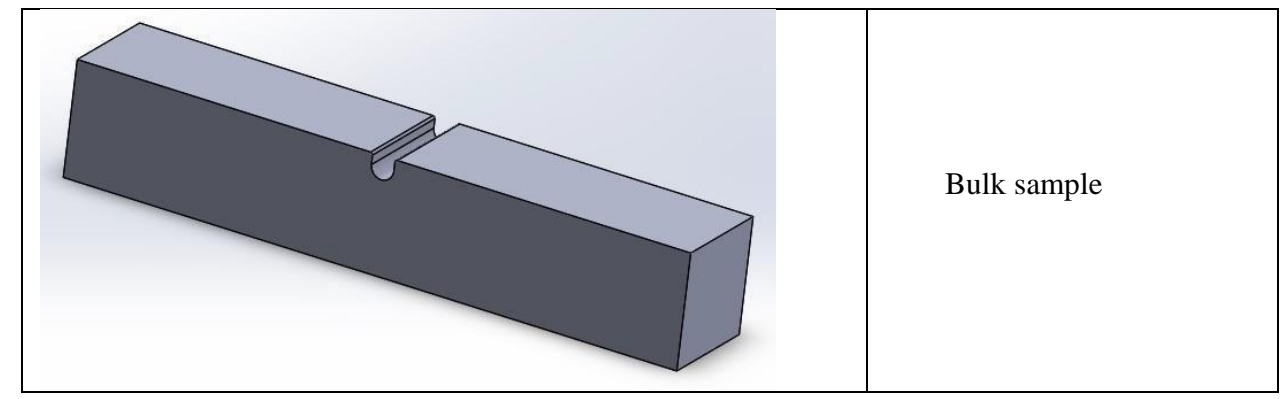




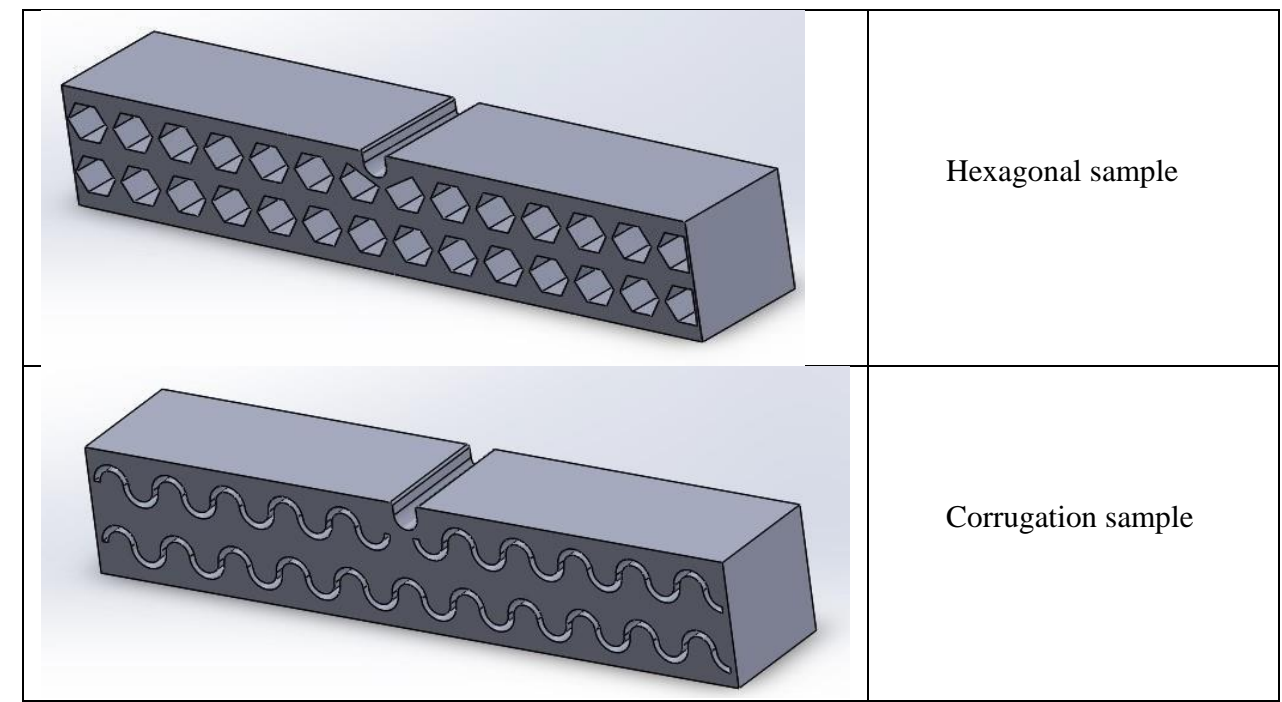

Figure 2. Toughness test samples

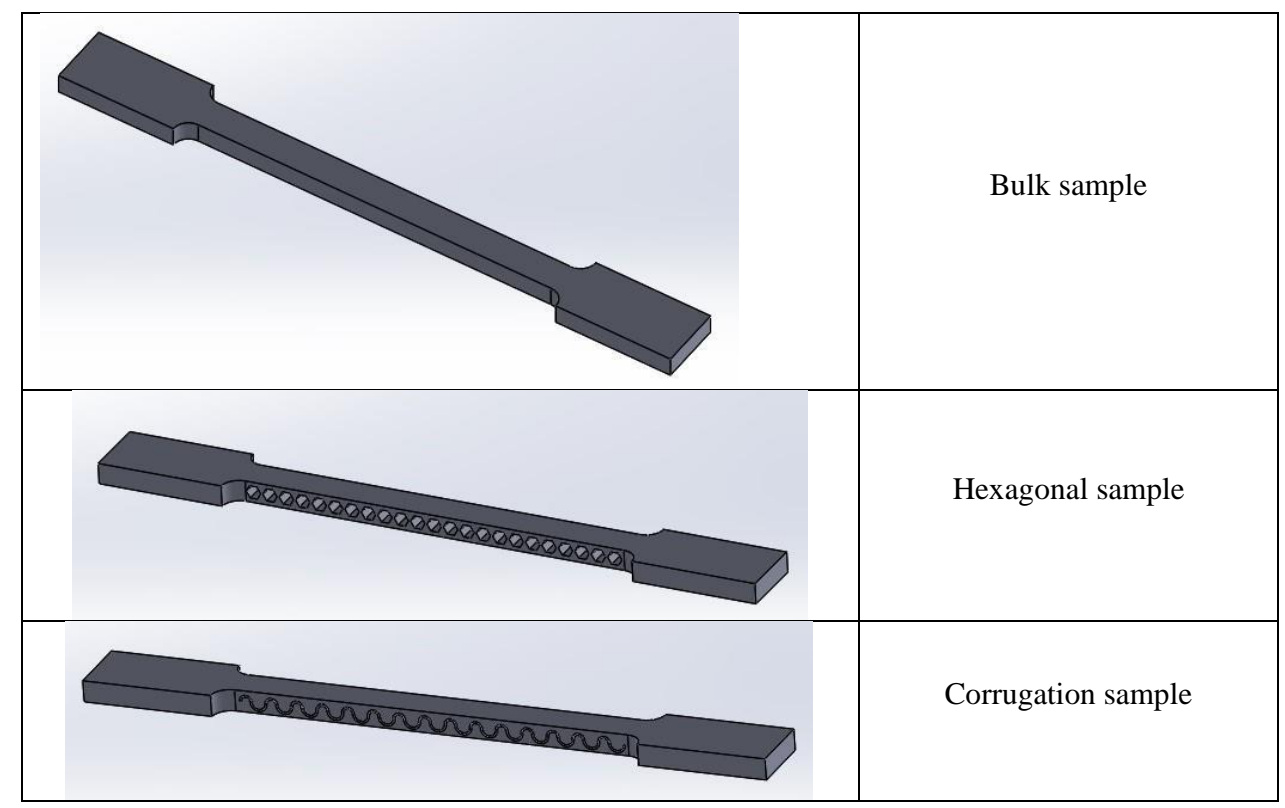

Figure 3. Tensile test samples

As can be seen from Figure 3, in order not to influence the results, the gap model was applied only in the calibrated area and not in the grip area in the tensile test device.

\subsection{Sample printing}

Next, we proceeded to the physical obtaining of the previously designed specimens using ABS "Silver" material from Sakata3D.

\section{Technical specifications form the producer [24]}

Material: ABS “Silver” (Chi Mei Polylac PA-757)

Nominal Diameter: $2.85 \mathrm{~mm}$

Diameter tolerance: $\pm 0.03 / 0.04 \mathrm{~mm}$

Density: $1.05 \mathrm{~g} / \mathrm{cm}^{3}$

Vicat's softening temperature: $105^{\circ} \mathrm{C}$

Printing recommended temperature: $225-245^{\circ} \mathrm{C}$ 
Plastic deformation threshold (ASTM D638): $470 \mathrm{~kg} / \mathrm{cm}^{2}$

Elongation at plastic deformation threshold (ASTM D638): 25\%

\section{CreatBot DX printer}

A CreatBot (Zhengzhou, China) DX-3D double-nozzle printer was used to obtain samples prints with a $0.4 \mathrm{~mm}$ layer thickness. The printing temperature for the filament (measured at the extrusion head) was $275^{\circ} \mathrm{C}$ and the bed temperature $90^{\circ} \mathrm{C}$, as recommended by the manufacturer.

For each type of sample, five prints were obtained at a printing speed of $30 \mathrm{~mm} / \mathrm{s}$.

The placement method and the obtained specimens are presented in the Figures $4 \div 6$.

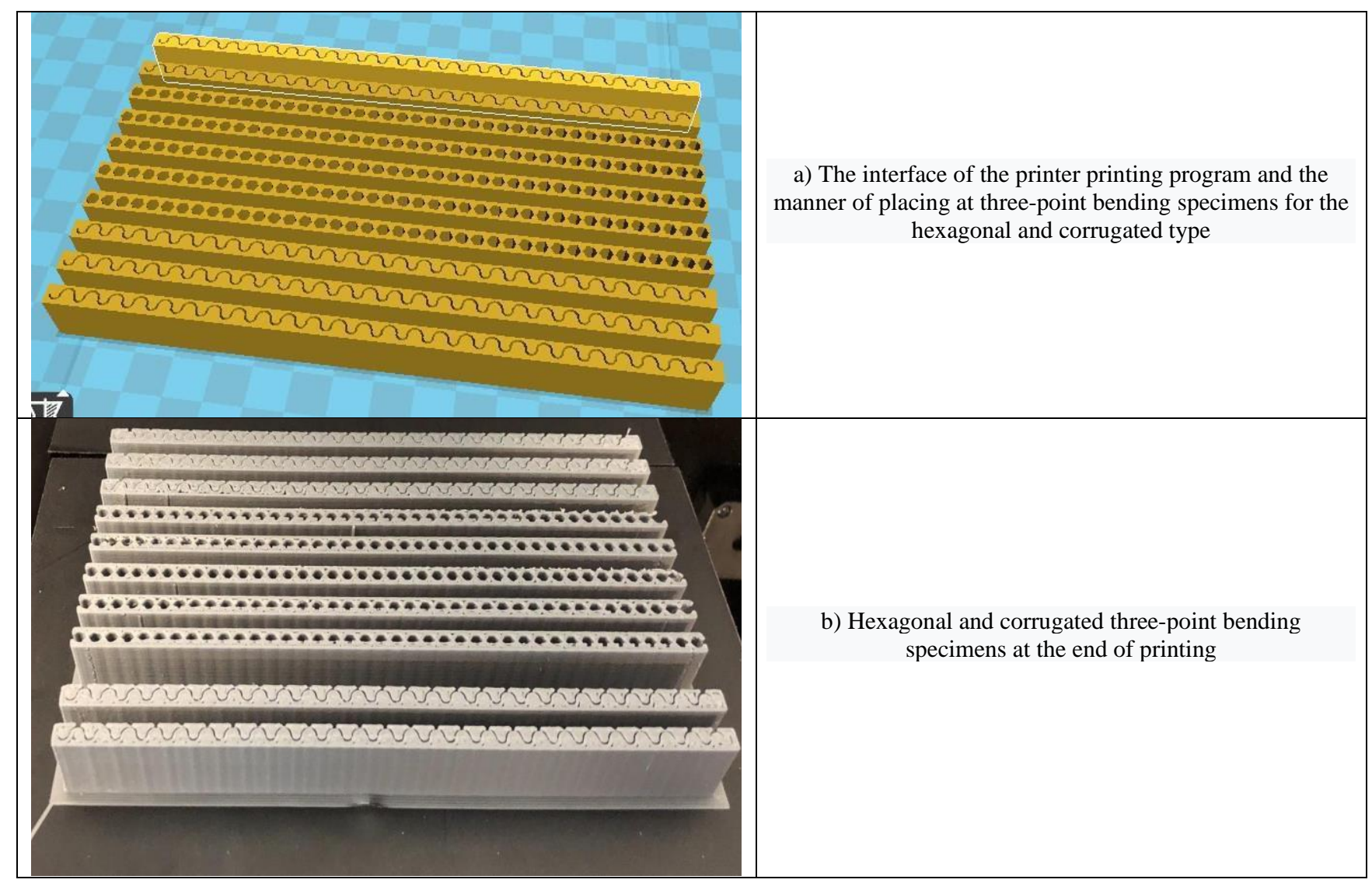

Figure 4. The manner of samples placement at three-point bending test

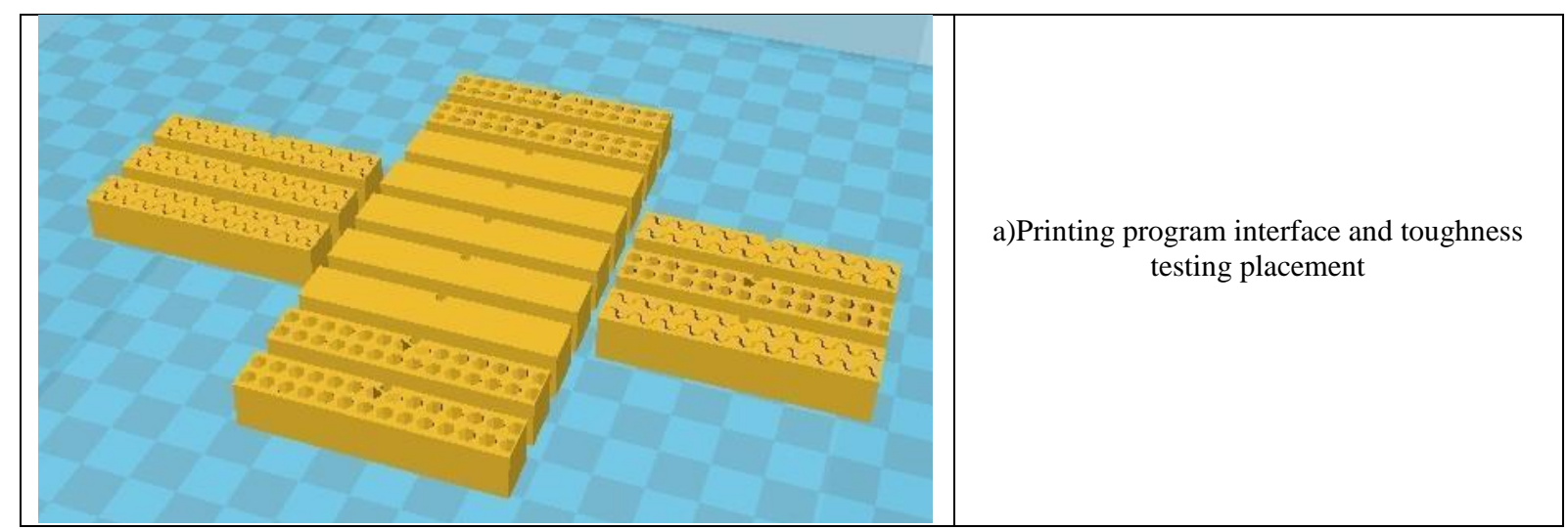




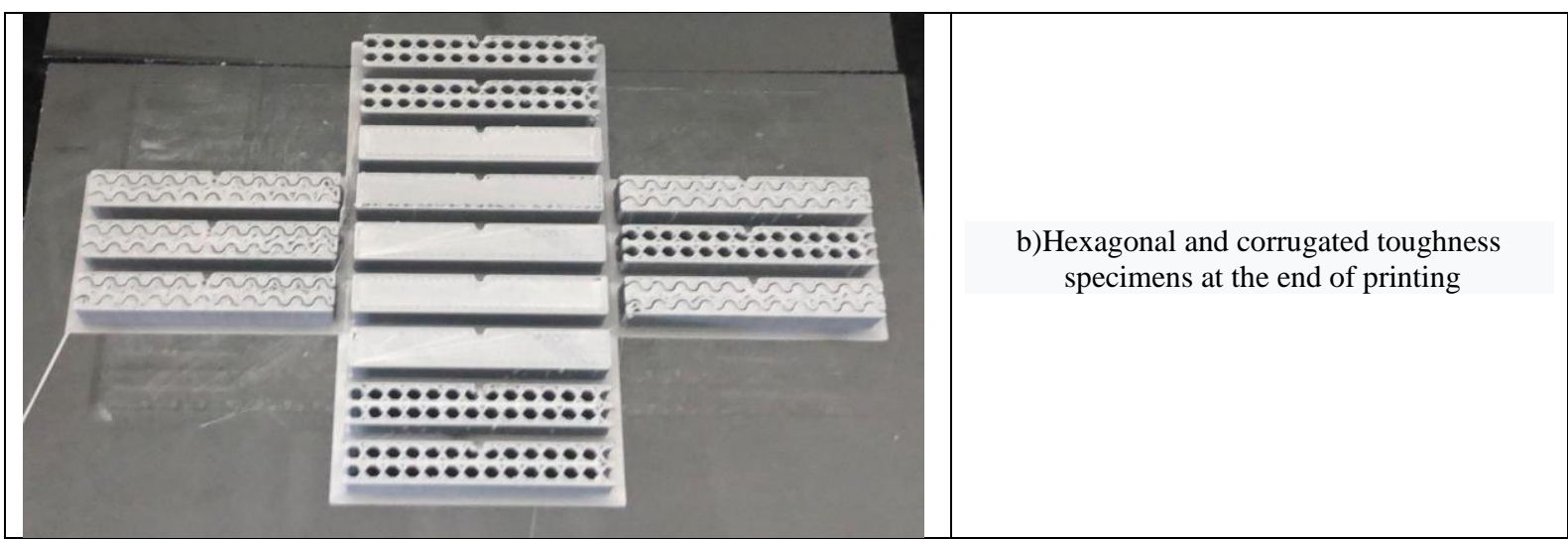

Figure 5. The manner of samples placement at toughness test

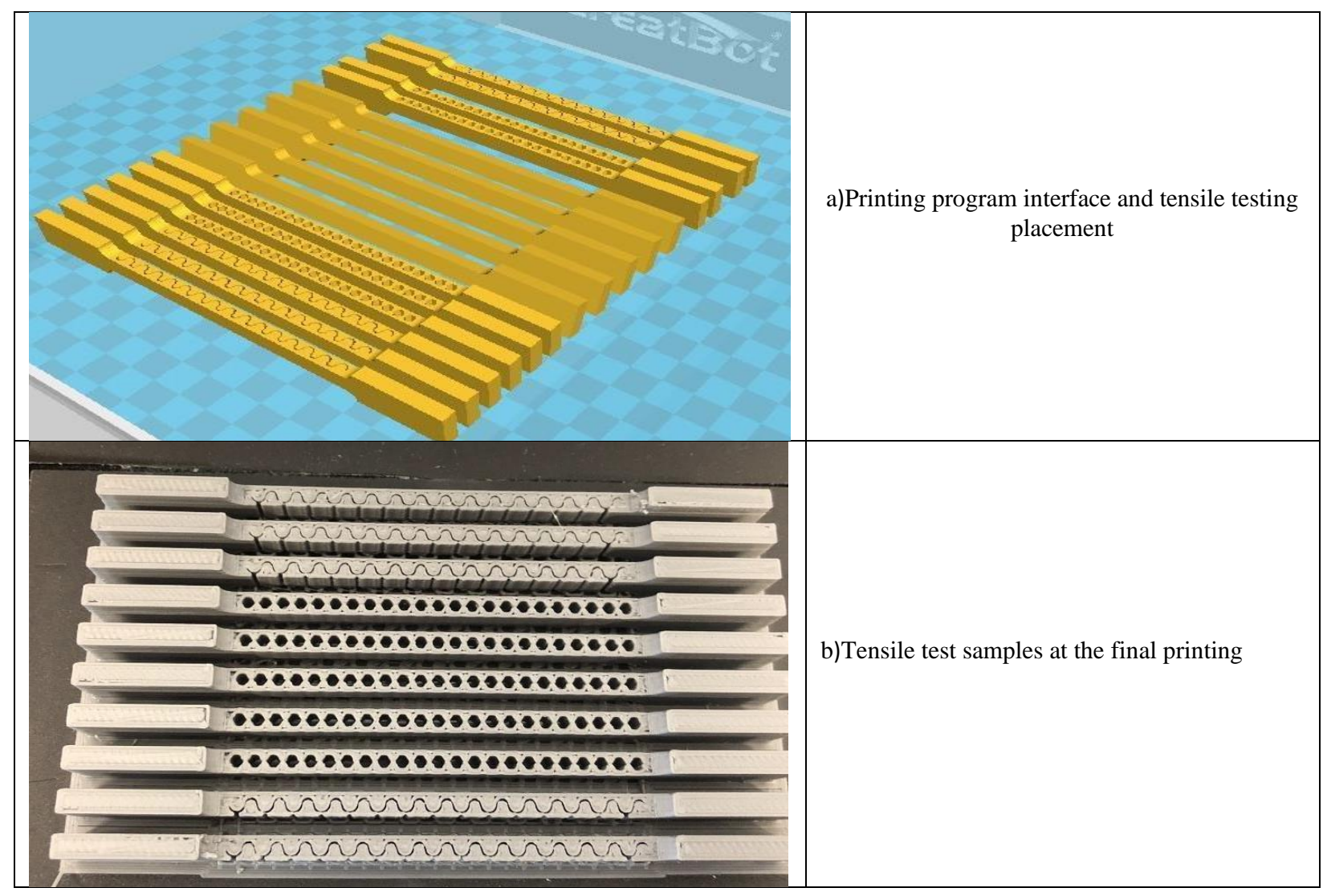

Figure 6. The manner of samples placement at tensile test

\subsection{Characterization methods}

The tensile and three-point bending tests were done on the WDW - $150 \mathrm{~S}$ universal testing machine. The testing machine can perform static and dynamic tests (including alternating fatigue). The test force is between 1 and $150 \mathrm{kN}$.

The toughness fracture was determined by Charpy hammer pendulum with the following characteristics: - arm length $\mathrm{l}=380 \mathrm{~mm}, \mathrm{~m}=6.784 \mathrm{~kg}$ and maximum measured energy $\mathrm{W}=5 \mathrm{kpm}$.

Relation 1 was used to calculate the toughness.

$$
A_{c U}=\frac{E_{c}}{d b} 10^{3}\left[\mathrm{~kJ} / \mathrm{m}^{2}\right]
$$




\section{Results and discussions}

\section{Determination of physical-mechanical properties}

For mechanical tests, a number of 5 specimens were obtained for each type of test. From the 5 values obtained, the minimum value and the maximum value were eliminated, and from the remaining 3 values the arithmetic mean was made.

Results concerning three-point bending test printing are given in Table 1.

Table1. Bending test results

\begin{tabular}{|c|c|c|c|c|c|c|c|}
\hline $\begin{array}{l}\text { No. } \\
\text { crt. }\end{array}$ & Sample & $\begin{array}{c}\mathbf{R}_{\mathbf{b b}} \\
{[\mathrm{MPa}]}\end{array}$ & $\begin{array}{c}\text { R}_{\mathrm{bb}} \text { medium } \\
{[\mathrm{MPa}]}\end{array}$ & $\begin{array}{c}\mathbf{E}_{\mathbf{b}} \\
{[\mathbf{G P a}]}\end{array}$ & $\begin{array}{c}\mathbf{E}_{\mathrm{b}} \text { medium } \\
{[\mathrm{GPa}]}\end{array}$ & $\begin{array}{c}\mathbf{f} \\
{[\mathrm{mm}]}\end{array}$ & $\begin{array}{c}\text { f medium } \\
{[\mathrm{mm}]}\end{array}$ \\
\hline 1. & Full 1 & 55 & \multirow{5}{*}{53.66} & 1 & \multirow{5}{*}{1} & 22 & \multirow{5}{*}{22.31} \\
\hline 2. & Full 2 & 51 & & 1 & & 22.4 & \\
\hline 3. & Full 3 & 55 & & 1 & & 23.2 & \\
\hline 4. & Full 4 & 58 & & 1 & & 22 & \\
\hline 5. & Full 5 & 47 & & 1 & & 22.55 & \\
\hline 6. & Hexagonal gaps 1 & 26 & \multirow{5}{*}{34} & 1.5 & \multirow{5}{*}{1.5} & 9.8 & \multirow{5}{*}{10.63} \\
\hline 7. & Hexagonal gaps 2 & 38 & & 1.5 & & 9.9 & \\
\hline 8. & Hexagonal gaps 3 & 34 & & 1.5 & & 11.5 & \\
\hline 9. & Hexagonal gaps 4 & 34 & & 1.5 & & 12.8 & \\
\hline 10. & Hexagonal gaps 5 & 34 & & 1.5 & & 10.5 & \\
\hline 11. & Sinuous gaps 1 & 23 & \multirow{5}{*}{16.33} & I & \multirow{5}{*}{ I } & 28.8 & \multirow{5}{*}{27.73} \\
\hline 12. & Sinuous gaps 2 & 26 & & / & & 29 & \\
\hline 13. & Sinuous gaps 3 & 11 & & l & & 26.9 & \\
\hline 14. & Sinuous gaps 4 & 15 & & / & & 27.5 & \\
\hline 15. & Sinuous gaps 5 & 11 & & / & & 25.5 & \\
\hline
\end{tabular}

where: $\mathrm{Fbb}=$ maximum force, $\mathrm{Rbb}=$ ultimate strength in bending $(\mathrm{Fbb}), \mathrm{E}=$ modulus of elasticity at bending, $\mathrm{F}=$ deflection $(\mathrm{mm})$

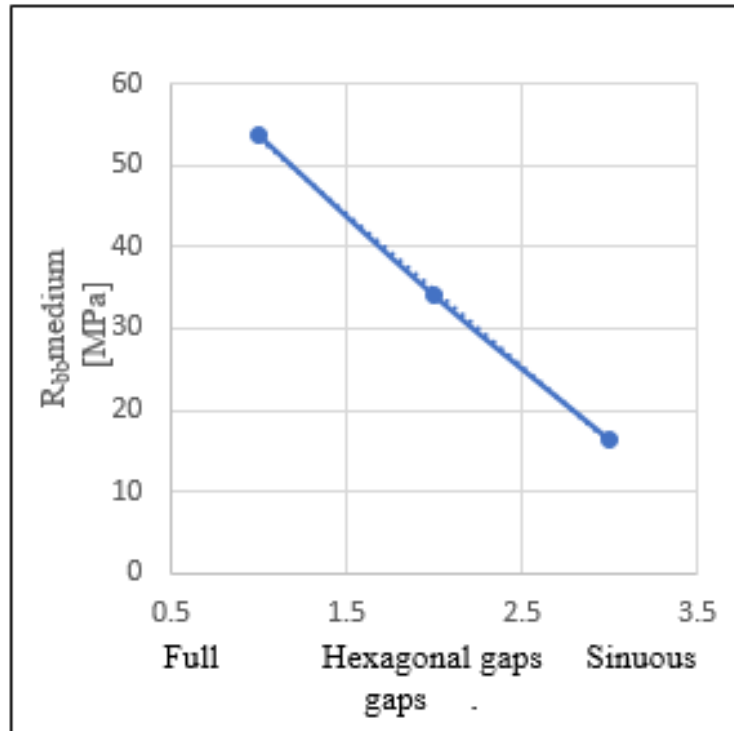

a.
Bend testing Report

\begin{tabular}{|c|c|c|c|}
\hline SanpleID & Inc_pl-1 & TestDate & $5 / 22 / 2018$ \\
\hline Operater & Pop rhat Alin & Type & Flat \\
\hline $51 z e(n n)$ & $16,5 * 5$ & $50\left(\sin ^{2}\right)$ & 82.50 \\
\hline $\operatorname{Ls}(\mathbf{m})$ & 100 & Fob (cks) & 0.15 \\
\hline $\mathrm{RBO}\left(\mathrm{KP}_{4}\right)$ & 55 & $F p b(\mathrm{ks})$ & 0.13 \\
\hline $\mathrm{Rpb}(\mathrm{KPa})$ & 47 & $E 0(G \mathrm{~Pa})$ & 1.0 \\
\hline$\pi(J)$ & 2570 & & \\
\hline
\end{tabular}

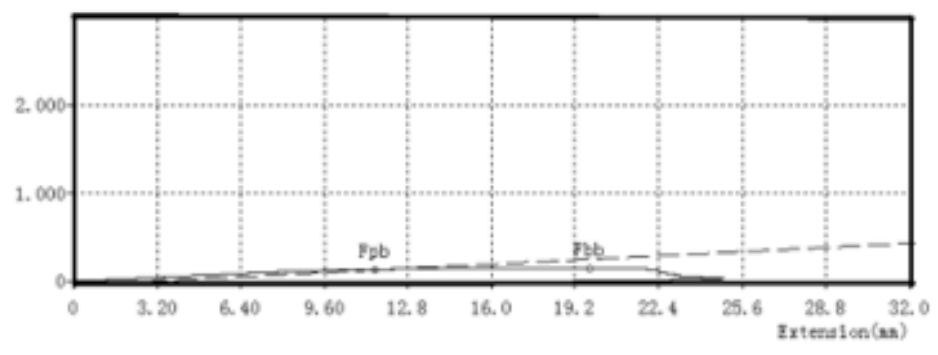

b.

Figure 7. Bending resistance. a. The graph with the values obtained for the three types of specimens and $b$. The result given automatically by the universal testing machine

One may remark that in the case of three-point bending test, the average resistance is almost equal compared to the reduction of material in the case of samples with hexagonal gap compared to solid ones, so it is recommended the configuration with hexagonal gaps to obtain marks required mainly for bending material consumption.

Results concerning toughness tests printing are given in Table 2. 
Table 2. Toughness test results

\begin{tabular}{|l|c|c|c|}
\hline $\begin{array}{c}\text { No. } \\
\mathbf{c r t}\end{array}$ & Sample & $\begin{array}{c}\text { Toughness strength } \\
{\left[\mathbf{k J} / \mathbf{m}^{2}\right]}\end{array}$ & $\begin{array}{c}\text { Average toughness strength } \\
{\left[\mathbf{k J} / \mathbf{m}^{2}\right]}\end{array}$ \\
\hline 1. & Full 1 & 2.5 & \multirow{2}{*}{2.82} \\
\hline 2. & Full 2 & 3.75 & \\
\hline 3. & Full 3 & 3.12 & \\
\hline 4. & Full 4 & 3.75 & \multirow{2}{*}{1.22} \\
\hline 5. & Full 5 & 2.45 & \\
\hline 6. & Hexagonal gaps 1 & 1.22 & \\
\hline 7. & Hexagonal gaps 2 & 1.22 & \\
\hline 8. & Hexagonal gaps 3 & 1.1 & \\
\hline 9. & Hexagonal gaps 4 & 1.26 & \multirow{2}{*}{1.22} \\
\hline 10. & Hexagonal gaps 5 & 1.22 & \\
\hline 11. & Sinuous gaps 1 & 1.31 & \\
\hline 12. & Sinuous gaps 2 & 1.22 & \\
\hline 13. & Sinuous gaps 3 & 1.22 & \\
\hline 14. & Sinuous gaps 4 & 1.22 & \\
\hline 15. & Sinuous gaps 5 & 1.05 & \\
\hline & & & \\
\hline
\end{tabular}

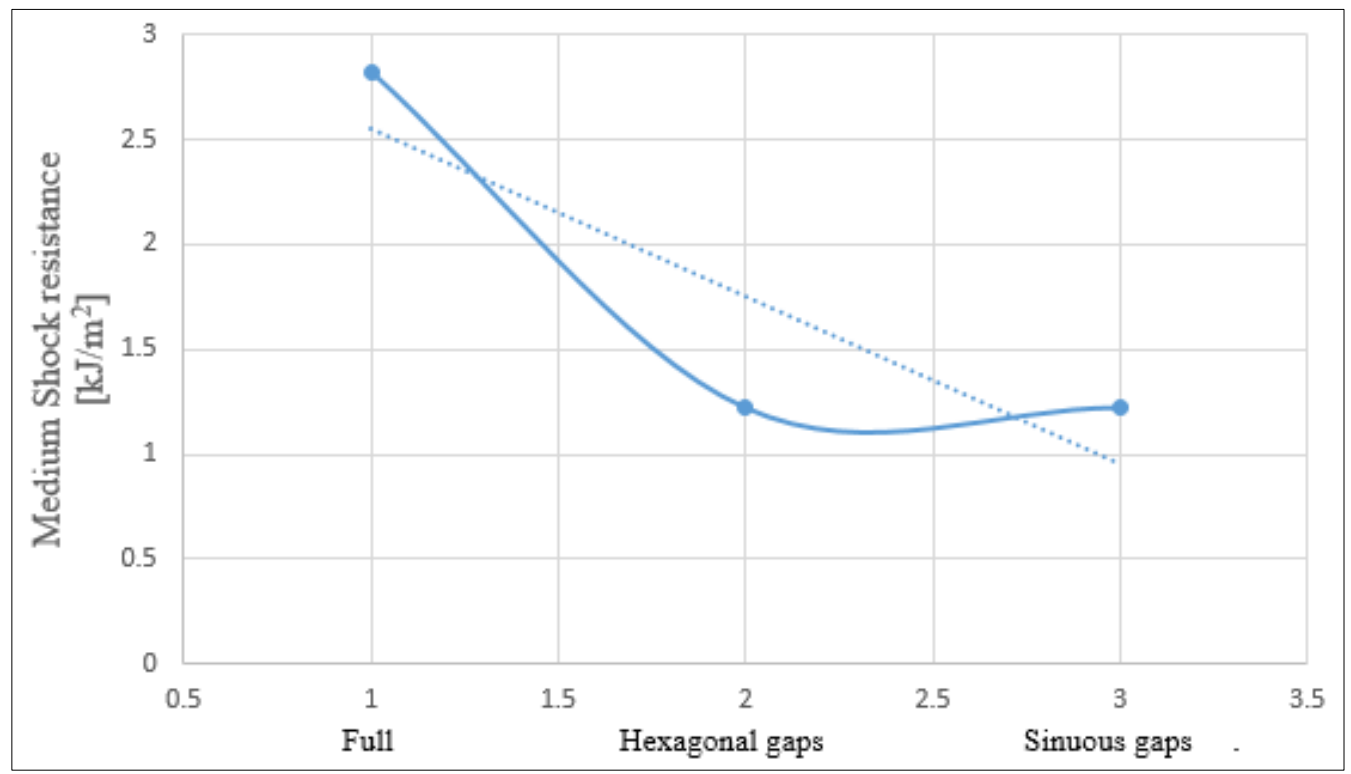

Figure 8. Toughness strength

In the case of the toughness test, the behavior is different in the sense that the average resistance is almost the same as the reduction of the material in the case of hexagonal gap samples. At a $30 \%$ reduction of the material used, the decrease of the value of the average resistance was of $37 \%$, instead the joint (maximum bending before breaking) decreased by 50\%. In the case of corrugated vacuum samples, the maximum bending strength decreased by $70 \%$ while the deflection increased, showing that the whole assembly has a more elastic behavior. Toughness strength is the property most influenced by the reduction of material (a decrease of over $50 \%$ in strength).

Results concerning the tensile tests printing are given in Table 3.

Table 3. Tensile tests results

\begin{tabular}{|c|c|c|c|c|c|c|c|}
\hline $\begin{array}{l}\text { No. } \\
\text { crt }\end{array}$ & Sample & $\begin{array}{c}\mathbf{R}_{\mathbf{m}} \\
{[\mathrm{MPa}]}\end{array}$ & $\begin{array}{c}\mathbf{R}_{\mathrm{m}} \text { medium } \\
{[\mathrm{MPa}]}\end{array}$ & $\begin{array}{c}\mathbf{E} \\
{[\mathbf{G P a}]}\end{array}$ & $\begin{array}{c}\text { E medium } \\
{[\mathrm{GPa}]}\end{array}$ & $\begin{array}{c}\mathbf{A}_{\mathbf{t}} \\
{[\%]}\end{array}$ & $\begin{array}{c}A_{t} \text { medium } \\
{[\%]}\end{array}$ \\
\hline 1. & Full 1 & 28 & \multirow[t]{5}{*}{$L^{2}-1$} & 2 & \multirow{5}{*}{2} & 4.7 & \multirow{5}{*}{4.56} \\
\hline 2. & Full 2 & 20 & & 1 & & 3.5 & \\
\hline 3. & Full 3 & 28 & & 2 & & 3.9 & \\
\hline 4. & Full 4 & 29 & & 2 & & 5.6 & \\
\hline 5. & Full 5 & 28 & & 2 & & 5.1 & \\
\hline 6. & Hexagonal gaps 1 & 13 & \multirow{2}{*}{14} & 1 & \multirow[b]{2}{*}{1} & 5.3 & \multirow{2}{*}{4.76} \\
\hline 7. & Hexagonal gaps 2 & 14 & & 1 & & 6.1 & \\
\hline
\end{tabular}




\begin{tabular}{|c|c|c|c|c|c|c|c|}
\hline 8. & Hexagonal gaps 3 & 14 & & 1 & & 3.5 & \\
\hline 9. & Hexagonal gaps 4 & 14 & & 1 & & 5.5 & \\
\hline 10 & Hexagonal gaps 5 & 14 & & 1 & & 3.1 & \\
\hline 1. & Sinuous gaps 1 & 9 & \multirow{5}{*}{9} & 1 & \multirow{5}{*}{1} & 4.1 & \multirow{5}{*}{3.36} \\
\hline 11 & Sinuous gaps 2 & 9 & & 1 & & 2.7 & \\
\hline 1. & Sinuous gaps 3 & 9 & & 1 & & 3.6 & \\
\hline 1. & Sinuous gaps 4 & 8 & & 1 & & 3.3 & \\
\hline $1:$ & Sinuous gaps 5 & 9 & & 1 & & 3.2 & \\
\hline
\end{tabular}

where: $\mathrm{Fm}=$ maximum force at tensile, $\mathrm{Rm}=$ fracture strength at tensile, $\mathrm{E}=$ modulus of elasticity at tensile test, $\mathrm{At}=$ elongation at tensile test

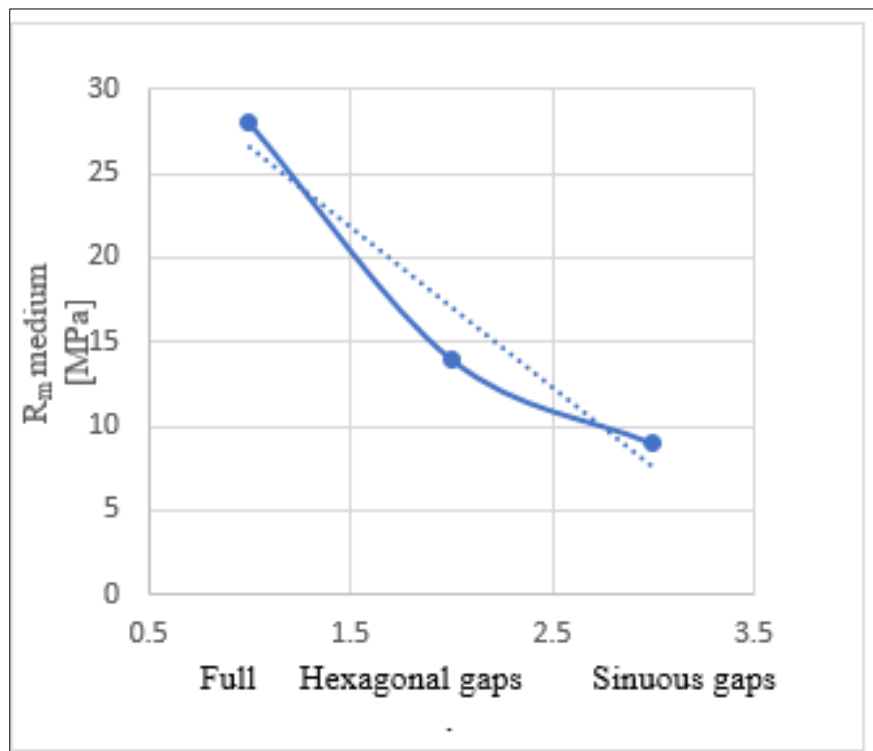

a.

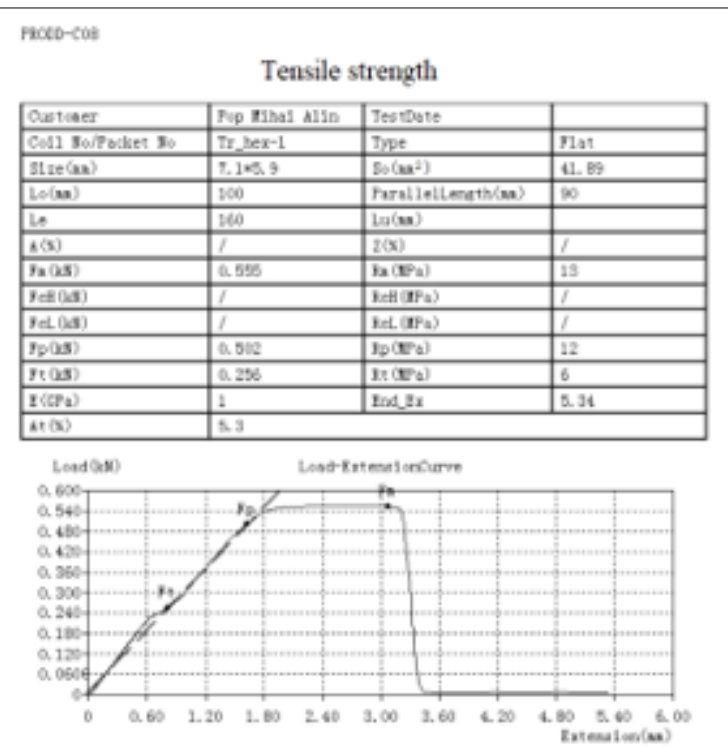

b.

Figure 9. Tensile strength a. The graph with the values obtained for the three types of specimens and $b$. The result given automatically by the universal testing machine

The maximum tensile strength (average) in the case of samples with hexagonal gap decreases by $50 \%$ even if the reduction of material was $30 \%$, instead the average elongation increases compared to the samples printed in full.

In the case of samples with corrugated gaps at a material reduction of $15 \%$, the maximum resistance to average tensile decreased by almost $70 \%$ while the average elongation by only $27 \%$ compared to the samples printed in full.

Partial conclusion: in the case of 3D printed parts subjected during tensile use, the full printed version is recommended $(100 \%)$.

\section{Conclusions}

The present paper resides in developing and characterizing two internal build architectures for 3Dprinted materials, namely a hexagonal model structure and a sinuous architecture with an amount of materials consumed 30 and $15 \%$ less. From our experiments there are the following conclusions:

-full specimens and two types of gaps were obtained where the reduction of material consumption was $30 \%$ for hexagonal gaps and $15 \%$ for corrugated gaps;

-in the case of the tensile test, it was shown that the maximum average strength of the test piece with hexagonal gaps was 50\% lower compared to that of the solid test piece but there was an increase in elongation before breaking, while in the case of with corrugated type gaps the resistance decrease was $70 \%$. If it is desired to obtain parts with high tensile strength, it is recommended to use the full variant and only if the part is not intensely requested, the hexagonal configuration can be used; 
- in the case of three-point bending test, the average resistance is almost equal compared to the reduction of material in the case of samples with hexagonal gap compared to solid ones, so it is recommended the configuration with hexagonal gaps to obtain marks required mainly for bending material consumption;

-for the parts required for toughness, only the full version is recommended.

Finally, it was determined that the part with an internal configuration with hexagonal type gaps kept the mechanical properties closest to the full specimen, while achieving a saving of $30 \%$ of the material used.

Acknowledgements: We hereby acknowledge the structural founds project PRO-DD (POS-CCE, O.2.2.1., ID 123, SMIS 2637, ctr. No 11/2009) for providing the infrastructure used in this work.

\section{References}

1.LIAN, Q., XIANGQUAN, W., DICHEN, L., Additive manufacturing technology. In Digital Orthopedics; Pei, G., Ed.; Springer: Dordrecht, The Netherlands, 2019, ISBN 9789402410761, doi:10.1007/978-94-024-1076-1_6.

2.SINGH, S., RAMAKRISHNA, S., SINGH, R., Material issues in additive manufacturing: A review. J. Manuf. Process., 2017, 25, 185-200, doi:10.1016/j.jmapro.2016.11.006.

3.NGO, T.D., KASHANI, A., IMBALZANO, G., NGUYEN, K.T.Q., HUI, D., Additive manufacturing (3D printing): A review of materials, methods, applications and challenges. Compos. Part B Eng. 2018, 143, 172-196, doi:10.1016/j.compositesb.2018.02.0124.

4. DECKERS, J., VLEUGELS, J., KRUTH, J.P. Additive manufacturing of ceramics: A review. J. Ceram. Sci. Technol., 2014, 5, 245-260, doi:10.4416/JCST2014-00032.

5.TORRADO, A. R., SHEMELYA, C. M., ENGLISH, J. D., LIN, Y., WICKER, R. B., \& ROBERSON, D. A., Characterizing the effect of additives to ABS on the mechanical property anisotropy of specimens fabricated by material extrusion 3D printing. Additive Manufacturing, 2015, 6, 16-29,

doi: 10.1016/j.addma.2015.02.001

6.SELVAMANI, S. K., SAMYKANO, M., SUBRAMANIAM, S. R., NGUI, W. K., KADIRGAMA, K., KANAGARAJ, G., \& IDRIS, M. S., 3D printing: Overview of ABS evolvement, AIP Conference Proceedings, 2019, Vol. 2059, No. 1, p. 020041, doi: 10.1063/1.5085984

7.CHARLES, A., BASSAN, P. M., MUELLER, T., ELKASEER, A., \& SCHOLZ, S. G. (2019, June). On the assessment of thermo-mechanical degradability of multi-recycled ABS polymer for 3D printing applications, In International Conference on Sustainable Design and Manufacturing, 2019, 363-373, doi: 10.1108/RPJ-08-2015-0098

8.FERRO, C. G., BRISCHETTO, S., TORRE, R., \& MAGGIORE, P., Characterization of ABS specimens produced via the $3 \mathrm{D}$ printing technology for drone structural components, Curved and Layered Structures, 2016, 3(1), doi: 10.1515/cls-2016-0014

9. POP, M.A., CROITORU, C., BEDÖ, T., GEAMĂN, V., RADOMIR, I., ZAHARIA, S.M., CHICOȘ, L.A., Influence of Internal Innovative Architecture on the Mechanical Properties of 3D Polymer Printed Parts. Polymers, 2020, 12(5):1129. https://doi.org/10.3390/polym12051129.

10. POP, M.A., CROITORU, C., BEDÖ, T., GEAMĂN, V., RADOMIR, I., COȘNIȚĂ, M., ZAHARIA, S.M., CHICOS,, A.L., MILOȘAN, I., Structural changes during 3D printing of bioderived and synthetic thermoplastic materials, J. Appl. Polym. Sci., 2019, 136, 47382.

11.GUESSASMA, S., BELHABIB, S., NOURI, H., Microstructure and Mechanical Performance of 3D Printed Wood-PLA/PHA Using Fused Deposition Modelling: Effect of Printing Temperature, Polymers 2019, 11, 1778.

12.WANG, K., LI, S., RAO, Y., WU, Y., PENG, Y., YAO, S., ZHANG, H., AHZI, S., Flexure Behaviors of ABS-based Composites Containing Carbon and Kevlar Fibers by Material Extrusion 3D Printing, Polymers, 2019, 11, 1878. 
13.SZUMAN, K., KRUCIŃSKA, I., BOGUŃ, M., DRACZYŃSKI, Z., PLA/PHA-Biodegradable Blends for Pneumothermic Fabrication of Nonwovens, Autex Res. J., 2016, 16, 119-127.

14.HUNG, K.C., TSENG, C.S., HSU, S.H., Advanced Healthcare Materials, John Wiley \& Sons: Hoboken, NJ, USA, 2014, Volume 3, pp. 1578-1587.

15.LIU, Z., LEI, Q., XING, S., Mechanical characteristics of wood, ceramic, metal and carbon fiberbased PLA composites fabricated by FDM, J. Mater. Res. Technol., 2019, 8, 3741-3751.

16.GNANASEKARAN, K., HEIJMANS, T., VAN BENNEKOM, S., WOLDHUIS, H., WIJNIA, S., FRIEDRICH, H., 3D printing of CNT-and graphene-based conductive polymer nanocomposites by fused deposition modeling, Appl. Mater. Today, 2017, 9, 21-28.

17.BRITES, F., MALÇA, C., GASPAR, F., HORTA, J.F., FRANCO, M.C., BISCAIA, S., MATEUS, A. CORK, Plastic Composite Optimization for 3D Printing Applications. Procedia Manuf., 2017, 12, 156-165, doi:10.1016/j.promfg.2017.08.020.

18.NAKAGAWA, Y., MORI, K. I., \& MAENO, T., 3D printing of carbon fibre-reinforced plastic parts, The International Journal of Advanced Manufacturing Technology, 2017, 91(5), 2811-2817,

doi: 10.1007/s00170-016-9891-7

19.LIAO, Y., LIU, C., COPPOLA, B., BARRA, G., DI MAIO, L., INCARNATO, L., LAFDI, K., Effect of porosity and crystallinity on 3D printed PLA properties, Polymers, 2019, 11, 1487.

20.HWANG, S., REYES, E. I., MOON, K. S., RUMPF, R. C., KIM, N. S., Journal of Electronic Materials, 2015, 44(3), 771-777.

21.CUIFFO, M. A., SNYDER, J., ELLIOTT, A. M., ROMERO, N., KANNAN, S., HALADA, G. P., Applied Sciences, 2017, 7(6), 579.

22.FENG, X., YANG, Z., ROSTOM, S. S., DADMUN, M., XIE, Y., WANG, S., Journal of Applied Polymer Science, 2017, 134(31), 45082.

23. SENATOV, F. S., NIAZA, K. V., ZADOROZHNYY, M. Y., MAKSIMKIN, A. V., KALOSHKIN, S. D., ESTRIN, Y. Z., Journal of the mechanical behavior of biomedical materials, 2016, 57, 139-148.

24.***https://www.eshop.formwerk.ro/catalog/materiale-238/sakata-3d-1000045 (last access november $\underline{2020)}$

25. VLĂSCEANU, D., BACIU, F., POPESCU, D., HADĂR, A., MARINESCU, R., Development and 3D Printing of an ABS Ergonomic Handle for Medical Use. A case study, Mater. Plast., 55(4), 2018, 630-633.

26. POPESCU, D., HADǍR, A., COTET, C., Manufacturing of ABS P400 Solid Cellular Structures with Closed Cells by Fused Deposition Modeling as Rapid Prototyping Process, Mater. Plast., 43(2), 2006, 175-179.

27. SAMYKANO, M., SELVAMANI, S. K., KADIRGAMA, K., NGUI, W. K., KANAGARAJ, G., \& SUDHAKAR, K., Mechanical property of FDM printed ABS: Influence of printing parameters. The International Journal of Advanced Manufacturing Technology, 2019, 102(9), 2779-2796,

doi: 10.1108/RPJ-10-2019-0267

28. DWIYATI, S. T., KHOLIL, A., RIYADI, R., \& PUTRA, S. E. (2019, December). Influence of layer thickness and $3 \mathrm{D}$ printing direction on tensile properties of ABS material. In Journal of Physics: Conference Series IOP Publishing, 2019, Vol. 1402, No. 6, p. 066014,

doi: 10.1088/1742-6596/1402/6/066014

29. LANZILLOTTI, P., GARDAN, J., MAKKE, A., \& RECHO, N., Enhancement of fracture toughness under mixed mode loading of ABS specimens produced by 3D printing, Rapid Prototyping Journal, 2019, doi: 10.1108/RPJ-09-2018-0247

$\overline{\text { Manuscript received: } 15.04 .2021}$ 